\title{
Educación Artística para la Formación Integral. Complementariedad entre Cultura Visual e Identidad Juvenil
}

\author{
Artistic Education for Integral Training. Complementarity between Visual Culture and \\ Youth Identity
Educação Artística para a Formação Integral. Complementariedad entre Cultura Visual, e Identidade Juvenil

\author{
José Miguel Mora Muñoz,, ${ }^{\mathrm{a}}$ Sonia Osses Bustingorry ${ }^{\mathrm{b}}$ \\ aUniversidad de La Frontera. Telf.: 62090228. Correo electrónico: josemiguelmora80@ gmail.com \\ bUniversidad de La Frontera. Telf.: 45-592841. Correo electrónico: sosses@ufro.c1
}

\begin{abstract}
RESUMEN
En el presente artículo se aborda a modo de ensayo el tema de la cultura visual y la formación estética en la postmodernidad desde una mirada epistemológica, considerando el arte como una forma de conocer el mundo y como objeto de conocimiento; se plantea el carácter ficcional de la realidad para sustentar el conocimiento a través de la formación estética; se aborda, además, la importancia que desde esta perspectiva teórica cobran la cultura visual y los nuevos medios en la forma de entender y plantear la educación artística y estética, orientada a la formación de la identidad y autonomía del sujeto.
\end{abstract}

Palabras clave: postmodernidad, estética, cultura, conocimiento, arte.

\begin{abstract}
In this article, the theme of visual culture and aesthetic training in postmodernity from an epistemological look/ glance is dealt with as an essay, considering art as a way of knowing the world and as an object of knowledge. The fictional character of reality is approached for supporting knowledge by means of aesthetic training as well as the importance achieved by visual culture and the new means of understanding and dealing with artistic and aesthethic education guided to the training of identity and subject autonomy from this theoretical perspective.
\end{abstract}

Key words: postmodernity, aesthetics, culture, knowledge, art.

\section{RESUMO}

Aborda-se, em forma de ensaio, o tema da cultura visual e a formação estética na Pós-modernidade desde uma visão epistemológica, considerando a arte como forma de conhecer o mundo e como objeto de conhecimento; propõe-se o caráter ficcional da realidade para sustentar o conhecimento por meio da formação estética. Aborda-se também a importância que desde esta perspectiva teórica cobram a cultura visual e os novos meios na forma de entender e propor a Educação Artística e estética, orientada à formação da identidade e autonomia do sujeito.

Palavras chave: pós-modernidade, estética, cultura, conhecimento, arte. 


\section{INTRODUCCIÓN}

Para abordar la temática de la cultura visual de los jóvenes en el marco de la educación artística y la formación integral, se requiere, en primer lugar, describir el tipo de sociedad en que se sitúa el análisis. La sociedad chilena, y el mundo en general, se encuentran en un momento de grandes cambios; la globalización y sus fenómenos se hacen sentir con fuerza, los mercados se abren, la información se libera y por esto, la educación debe responder por la capacidad de los individuos para desenvolverse en un medio cada vez más exigente. Al igual que otras sociedades latinoamericanas, Chile se enmarca en una economía y cultura de carácter mundial; algo que se preveía a fines del siglo $\mathrm{XX}$ hoy es una realidad y, con ello, se produce un proceso de aculturación que remueve los cimientos de la cultura tradicional. Se puede entender la globalización como "la intensificación de las relaciones económicas, políticas, sociales y culturales mundiales, impulsadas por la dinámica de los mercados (de capitales sobre todo), revolución tecnológica, redes internacionales productivas, sociedad de la información y el conocimiento y movilidad global de los factores productivos" (Moreno 2001: 109); en esta dinámica, las tecnologías de la información y las comunicaciones, el conocimiento, y la cultura visual generan grandes cambios en el modo de percibir la realidad.

La velocidad de los cambios que provoca la globalización, el culto a la individualidad, el cuestionamiento a las verdades y los procesos de destradicionalización e innovación constante, están haciendo tambalear las certezas de la sociedad local. Según Urreiztieta (2004), esto está generando grandes incertidumbres y riesgos en las vidas, lo que trae consigo incómodas consecuencias psicológicas, emociones y vivencias que denotan el malestar postmoderno: incertidumbre, ambigüedad, ansiedad, falta de seguridad, horizonte de vida incierto, dependencia, carencia de control y predecibilidad. Las dinámicas que se generan a nivel socio-económico producto de estas transformaciones, pueden llegar a afectar la realidad en que se contextualiza la educación de una forma mucho más rápida y potente que en otros tiempos; esto significa que la velocidad de los cambios y la fuerte motivación económica que los mueve, genera tensiones que obligan a revisar lo que sucede en nuestra forma de ver la educación y las interrelaciones que se producen a partir de ella con los medios de comunicación y de producción estética.

Efectivamente, los medios de comunicación no sólo difunden la información y la interpretación de los hechos sociales y el conocimiento considerado la "verdad" y lo "verídico", sino que, además, transmiten valores, no sólo desde una perspectiva ética o formativa, sino que "valor" en términos de intercambio social en la sociedad de consumo, "los estándares de comportamiento y los estereotipos humanos, así como también y, sobre todo, los estándares de consumo deseables, homogeneizando paulatinamente las estructuras psicosociales valóricas, perceptivas, motivacionales y actitudinales, e incluso, utilizando y modificando en grado desconocido los sustratos instintuales de los seres humanos" (Cooper 2007:26). A partir de los antecedentes señalados se podría inferir que Chile y otros países latinoamericanos se encuentran en especial desventaja frente a esta realidad, ya que sus sociedades son permanentes consumidores de la producción audiovisual, informativa y estética de los países que dominan el mercado; "los medios de comunicación imponen normas de conducta, instalan el conformismo social, canalizan actitudes. Los avances informativos son de tal rapidez y envergadura que todo lleva a la sociedad de la información, de la que son pacientes los países y sociedades menos 
preparadas" (Cebrián 1999:8). La globalización permite, a través de las nuevas tecnologías de la información, un flujo constante y sin límites para la información producida, sin una regulación de sus contenidos y cargas valóricas.

La industria del ocio o la entretención, que se podría denominar "seudocultura", la cual se ha transformado en una especie de ideología dominante, ha dado lugar a fenómenos como el debilitamiento del modelo educativo humanístico-racional, "sustituido por una formación -seudoformación- en la que se incentiva lo técnico y se abarata el proceso de formación de la mano de obra por parte de las empresas, ya que será el Estado el que transforme el sistema educativo en esa dirección" (Muñoz 1993:7), dejando la construcción de la identidad desvinculada de la cultura o, más bien, en manos de los intereses económicos de los medios masivos de comunicación. Esto involucra la producción visual y la forma en que vivimos la experiencia estética, ya que junto con la globalización de la cultura y la masificación de los medios se afecta directamente a la población a través de la imagen, siendo ésta altamente deformante si no se educa para su valoración responsable; la educación debe enfrentarse a lo que Moreno (2001) describe como una "universalización de las imágenes y mensajes audiovisuales pero en una versión "macdonalizada" de adopción de valores, estilos culturales, íconos e imágenes planetarias proyectada por el modelo estadounidense de consumo muy estandarizado, fetichizado y con baja calidad cultural".

Al enfrentar esta realidad, se ha planteado que la educación no sólo debe formar individuos capacitados para desenvolverse en un medio o sector productivo específico, sino que, además, debe formar personas capacitadas para la vida tanto en el plano intelectual como emocional, es decir, en su crecimiento integral como persona. "Sin lugar a dudas, estamos enfrentados a una búsqueda de nuevos paradigmas al interior de la sociedad en su conjunto. El paradigma que está hoy en vías de cambio y que privilegia una concepción racionalista del ser humano, ha dominado nuestra cultura y nuestra convivencia social por siglos. Este modelo, más allá de sus evidentes aportes al desarrollo científico tecnológico, ha conducido a un profundo desequilibrio entre lo racional y lo emocional" (Magendzo et. al., 1998: 7). Este desequilibrio se podría estar reflejando en una visión reduccionista e infantilizada de lo que es la educación artística. No basta con conceder el privilegio de la razón a las disciplinas científicas y la emoción a las disciplinas artísticas. El mundo de hoy requiere integrar ambos aspectos en las distintas áreas de conocimiento.

Considerando lo anterior, el objetivo de este trabajo es reflexionar sobre la educación artística, la cultura visual y la formación estética en la postmodernidad desde una mirada epistemológica, considerando el arte como una forma de conocer el mundo y como objeto de conocimiento. Para hacerlo, partiremos por plantear algunas relaciones entre la pedagogía el arte y el conocimiento. Posteriormente, revisaremos a través de la epistemología, el carácter ficcional de la realidad para sustentar el conocimiento a través de la formación estética. Se aborda, además, la importancia que desde esta perspectiva teórica cobran la cultura visual y los nuevos medios en la forma de entender y plantear la educación artística y estética. Finalmente, pasaremos a plantear algunas reflexiones en torno a la educación en artes visuales, cultura visual y construcción de la subjetividad juvenil. 


\section{PEDAGOGÍA, ARTE Y CONOCIMIENTO}

Desde la perspectiva de la pedagogía del arte se observa cómo el currículum heredado de la modernidad, se basa y se extiende en el desarrollo del pensamiento y la racionalidad técnica, mientras que los aspectos que intervienen en el desarrollo personal del sujeto quedan relegados a un segundo orden de importancia; no cabe duda que la necesidad de una fuerte formación valórica, afectiva, emocional, de subjetivación y de construcción de una identidad autoconsciente, cobran relevancia en un mundo en que los estragos de la racionalidad se expresan con fuerza en las nuevas generaciones. Esta necesidad de potenciar los aspectos señalados en la enseñanza no buscan otra cosa que la formación integral del sujeto, entendiendo que el conocimiento no es parcelado ni de exclusiva propiedad de la razón; el conocimiento expresado en el desarrollo cultural es el reflejo del desarrollo del conjunto de capacidades humanas en una síntesis colectiva, por lo tanto, no se trata de escoger o reemplazar la razón y el pensamiento por el sentimiento y la intuición. "Se trata de revalorizar las segundas para buscar una síntesis entre dimensiones psíquicas que en la modernidad tienden a operar de manera escindida. No serían entonces el sentimiento y la intuición las funciones que, por si mismas, potencializarían el desarrollo humano; éste se daría a través de la tensión entre funciones que tienden a operar en forma independiente y, posteriormente, la integración entre ellas, proceso que Jung denominó "función trascendente" (Sáenz, 2003: 246). Esta función trascendente, tiene especial relación con la actividad artística y la estética, siempre y cuando, éstas se consideren como un medio para conocer y comprender el mundo y a sí mismo.

El arte, entendido desde una dimensión pedagógica, es una actividad de desarrollo subjetivo del conocimiento y las potencialidades humanas; esta subjetivación es la forma en que el individuo asume el conocimiento como propio, que lo hace ser reflexivo y le permite actuar sobre sus estados físicos mentales y espirituales. La subjetivación la asumimos en el sentido que le ha dado Foucault citado en Sáenz et al. (1996: 29) a las tecnologías del yo, como aquellas "que permiten a los individuos efectuar por cuenta propia o con la ayuda de los otros, cierto número de operaciones sobre su cuerpo y su alma, pensamientos, conducta o cualquier otra forma de ser, obteniendo así una transformación de sí mismos, con el fin de alcanzar cierto grado de felicidad, pureza, sabiduría, o inmortalidad; en pocas palabras se trataría de "el modo en que un individuo actúa sobre sí mismo".

La escuela moderna se vuelca principalmente hacia el desarrollo del pensamiento y la razón, sin embargo, la subjetividad de los estudiantes cobra su espacio, reclama un ámbito de desarrollo que la escuela tiende a negar o, en muchos casos, a restringir; esta necesidad de comprensión y de aprendizaje subjetivo está vinculado con las relaciones interpersonales, las relaciones con el entorno y con la información circundante, es un impulso que busca definir la identidad de los sujetos. Si esta necesidad no es cubierta y desarrollada, se manifestará en los conflictos de la personalidad los cuales se acrecientan y se hacen particularmente notables en la adolescencia. "Buena parte de la pasividad, los juegos, las burlas y las ironías de los estudiantes están dirigidas a energizar estas formas de expresión de lo humano. Se trata de un esfuerzo, fallido en la mayoría de los casos, por humanizar el ámbito escolar y por no permitir la derrota de la subjetividad. Para los estudiantes más introvertidos, así como para aquellos en los que dominan las funciones del sentimiento y la intuición, se trata de una resistencia en que está en juego 
su identidad psicológica" (Sáenz, 2003: 252). Las asignaturas artísticas son una fuente de desarrollo innegable; su orientación debiera estar puesta en el desarrollo integral del sujeto, vinculando los aspectos cognitivos y subjetivos, ya que, para lograr aprendizajes significativos, el estudiante debe tener la capacidad de subjetivar los contenidos, hacerlos suyos; apropiarse del conocimiento es un acto subjetivo. El arte es una forma de conocimiento que estimula el desarrollo de estas habilidades encauzando las necesidades psicológicas afectivas e intuitivas de los estudiantes en la construcción de su identidad.

A continuación, pasaremos a revisar a través de la epistemología, el carácter ficcional de la realidad para sustentar el conocimiento a través de la formación estética. El propósito es esbozar un marco conceptual que integre la actividad artística y estética en el campo del conocimiento.

\title{
3. LA FICCIÓN COMO CONOCIMIENTO: TRAS LOS GIROS DE LA EPISTEMOLOGÍA
}

\begin{abstract}
"Si es la experiencia la que pone al pensamiento fuera de quicio, insubordinándolo y, con ello, al propio mundo ("todo es posible"), en tal caso, es la experiencia la que debe ser disciplinada en la puesta en forma del propio pensamiento, su sujeción: tarea de autodisciplina, entonces, que normaliza la experiencia en la representación" (Molina, 2004: 189).
\end{abstract}

El contexto postmoderno puede convertirse en un laberinto sin salida para quienes no encuentran la forma de aprender a ser y a relacionarse en este mundo confuso. "El momento postmoderno es una especie de explosión de la episteme moderna en el que la razón y el sujeto - como detentador de la "unidad" y "totalidad" - vuelan en pedazos" (Wellmer, 1995: 53) las formas artísticas al acercarse al conocimiento, lo hacen explorando en las formas mismas del conocer de la experiencia estética y artística. "El término postmoderno sigue teniendo sentido, y este sentido está ligado al hecho de que la sociedad en que vivimos es una sociedad de comunicación generalizada, la sociedad de los medios de comunicación" (Vattimo, 1995: 9).

Según Baudrillard (1978), la imagen no es lo que se percibe ni lo que se deriva de su análisis formal, es el reflejo de una realidad básica, enmascarada y convertida en puro simulacro; de ahí que la preocupación principal de la educación en Artes Visuales no sea ya el producto artístico ni su análisis histórico o formal, sino las operaciones, los procesos y las habilidades que se desenvuelven en su existencia como experiencia. “¿Cómo es posible tomar algo por verdadero, es decir, cómo es posible no la verdad en sí misma, sino su experiencia, en tanto ésta es algo que le ocurre a alguien? Si la verdad acontece en la relación, entonces es la relación la que debe estar en orden. En esta medida el orden de la percepción no lo es sólo del mundo, sino que constituye al sujeto mismo. Así, la subjetividad puede estar referida a priori a un mundo en tanto la unidad de éste encuentra su fundamento en la unidad de la conciencia" (Molina, 2004: 190).

Tras haber conocido el mundo a través de un cristal que proponía un conocimiento verdadero y acreditado gracias a la razón, las bases de la fe moderna comienzan a perder su firmeza indiscutible al surgir en el pensamiento de la época las perspectivas provocadas al someter la razón a juicio; estas perspectivas llevan a la desfundamentación lingüística de la experiencia. "Al sustituir la conciencia, como objeto de reflexión y de análisis, por 
el lenguaje, y al suprimir la búsqueda de explicaciones nomológicas de la naturaleza por el acontecer del sentido que se comprende siempre de manera diferente, la ciencia ha logrado liberarse de las abstracciones de la teoría, proponiendo nuevas interpretaciones del conocimiento y de la experiencia. La epistemología que surge entonces, rompe también con la comprensión positivista y cientificista que hace de la ciencia una actividad de dominio y control racionales de la naturaleza y del hombre" (Bentolila, 2006: 2). Se trata de la epistemología de la duda, o bien el comienzo del estado de incertidumbre que comienza a tomar forma hasta nuestros días, generando importantes cambios de foco a la hora de plantearnos la posibilidad de conocer los medios y los objetos de éste.

Algunos de los autores que aportan nuevas interpretaciones del conocimiento y de la experiencia y que se perfilan hacia una visión comprensivista de las ciencias, destacan por el giro pragmático del lenguaje en Wittgenstein y el giro hermenéutico que iniciara Heidegger y que sería desarrollado por Gadamer. Posteriormente Derrida llevaría a un extremo el pensamiento de Heidegger con una vuelta al logocentrismo, proponiendo el lenguaje siempre como un lenguaje pensado que presenta dicotomías que relativizan su significado. "Derrida lleva todo esto a sus últimas consecuencias: si la diferencia es la que posibilita toda comunicación posible, ésta no se puede reducir a ninguna presencia, y la diferencia se convierte por tanto en la nueva estructura profunda. Sólo que Derrida no habla de estructura sino más bien de una teoría probabilística, una "teoría de los juegos" que permita saber lo que podría suceder allí donde no hay ninguna estructura determinada. Aprehender lo irracional con una estructura concreta sería disparatado, por eso al no-origen se llega mediante el juego" (Muñoz, 1998: 5).

Así, este autor pone énfasis en la posibilidad de develar el ser en el lenguaje, creando con ello la indeterminación del ser y del lenguaje sin una posición única, lo que expresa de la siguiente manera: "Tal es la cuestión: la alianza del habla y del ser en la palabra única, en el nombre al fin propio. Tal es la cuestión que se inscribe en la afirmación jugada de la diferencia [différance]. Se refiere a cada uno de los miembros de esta frase; "El ser/habla/en todas partes y siempre/a través de/toda/lengua" (Derrida, 1968: 26), el neologismo [différance] refiere al hecho que algo no pueda ser simbolizado ya que desbordaría la representación, de lo que surge el hecho de que una palabra o una imagen sólo significa algo al diferir con otra.

Por otro lado, Rorty (1996) acoge los postulados de Heidegger y Derrida para ofrecer una visión neopragmatista del lenguaje, que implicaría una carencia de significado y de sentido único, por lo cual no se puede alcanzar una verdad unívoca; con esto desmantela las preguntas metafísicas y busca su asidero en cuestiones culturales y políticas. "Rorty ha considerado inútil haber seguido la senda de la verdad como herencia platónica a través de la filosofía, puesto que el mundo de hoy exige una visión centrada en los aspectos ético y político y no en lo epistemológico. Nuestro pensador considera necesario la construcción de nuevos lenguajes, crear nuevas metáforas que permitan una manera distinta de pensar aceptando que la realidad, la historia, la vida misma y todo lo que concierne a la cultura son resultados de la contingencia y del azar" (Ávila, 2002: 23).

De sus planteamientos se desprende lo que sería una irracionalidad y es acusado de relativista; de hecho, el autor se hace cargo de estas impresiones al desestimar la verdad absoluta y cualquier otra desde el racionalismo tradicional. Como lo expresa Ávila (2002: 23): "Lo que ocurre es que el léxico del racionalismo ilustrado parte de distinciones tradicionales como absolutismo y relativismo, moralidad y conveniencia, que 
el progreso intelectual de nuestro tiempo ha cuestionado, ya que la argumentación propia de la filosofía de las luces se basa en las nociones de verdad, racionalidad y obligación moral, que son contrarias al uso de la metáfora y a la creación de sí mismo asociada a la racionalidad estético-expresiva". De alguna forma, los esfuerzos por librarse de la razón totalizante conducen irrevocablemente a una nueva forma de entender la realidad y al ser humano, una nueva forma de conocer que se despierta en la irracionalidad de sus propios mecanismos cognoscitivos.

"Sin embargo, se debe entender el irracionalismo como una nueva conquista. Pese a lo ingente de los nuevos continentes descubiertos, pese a la apariencia inabarcable de la nueva tarea que se despliega allende los nuevos horizontes, al menos las expediciones están emprendidas y el logocentrismo ha sido rebasado. El desconcierto epistemológico es comprensible: son los efectos de haber liberado a la ficción como instrumento cognoscitivo, de haber indultado a la metáfora" (Muñoz, 1998: 5).

Según lo planteado hasta aquí, tomando en cuenta la relevancia y predominio de la estética en la cultura actual, se podría situar lo que Vásquez Rocca denomina el giro estético de la epistemología: "La expansión de las categorías estéticas proporciona el único paradigma posible en las nuevas condiciones de nuestro trato con la realidad. Mi opinión es que nuestra concepción — postmoderna - de la realidad, nuestra «filosofía primera», se ha vuelto, en un sentido elemental, estética. «Filosofía primera» es el título de aquel capítulo de la ciencia en donde se hacen las afirmaciones fundamentales sobre la realidad" (Vásquez Rocca, 2006: 46). Esta expansión de las categorías estéticas comienza como una expansión de las categorías artísticas, poniendo en tensión el concepto de realidad y representación.

El problema de la representación y significación en el arte comienza a generar una tensión o más bien una relación entre ficción y conocimiento, las nuevas formas de entender el arte proponen una deconstrucción constante de sí mismo y de sus propios lenguajes que son, a su vez, la representación de lo real como representación en sí. Es decir, no hay una realidad o un ser al cual el arte se pueda referir sino más bien una ficción en constante devenir, en constante desmantelamiento, donde el juego del lenguaje es capaz de crear una "realidad otra" que busca comprenderla en su devenir. "Las obras de arte no son, pues, objetos aislados del mundo y de su acontecer, sino más bien, organizaciones imaginarias del mundo, las que para ser activadas requieren ser puestas en contacto con un modo de vida, con un fenómeno concerniente al ser humano, de modo tal que, como se hace evidente en la postmodernidad, arte y vida se codeterminan y se copertenecen" (Vásquez Rocca, 2006: 48).

Ya que existe esta estrecha relación entre los objetos estéticos o artísticos de cualquier tipo con la realidad y la vida, surge la necesidad de considerarlos con una base cultural, lo que se desprende del hecho de que hoy en día la producción estética es objeto de consumo, ya sea por la publicidad, la cultura, la política y los objetos cotidianos. Estos productos estéticos son la realidad cotidiana. Cuando nos referimos al mundo, nos referimos a él, en tanto forma y contenido, como un conjunto de objetos presenciales construidos y deconstruidos según una perspectiva dada. "Los objetos artísticos poseen —en este sentido - una particular dimensión ontológica y cognoscitiva, adquiriendo el estatuto de huella antropológica, de síntoma histórico-cultural de determinadas sensibilidades propias de la comunidad que las realizó. En las producciones artísticas - con sus resonancias filosóficas y espirituales - es posible leer la sensibilidad de una época o, si se quiere, 
la condición psicológica de la humanidad en una situación dada" (Vásquez Rocca, 2006: 48). Desde este punto de vista se advierte la posibilidad de que nuestras organizaciones imaginarias del mundo no sean distintas ni otra cosa que el mundo en sí; de hecho, si existiera alguna diferencia entre el mundo real y el ficticio no seria más que por una categorización de estas representaciones, o una diferenciación conveniente. Siendo así, "Un objeto fantástico no tiene por qué ser distinto de un objeto real: la diferencia entre ambos se reduce a que una misma cosa nos la representamos como existente o como inexistente" (Ortega y Gasset, 1962: 143).

Siguiendo con las reflexiones de Vásquez Rocca al respecto, él nos dirá que "nuestra concepción empírica del mundo se basa en presupuestos fundamentalmente erróneos. En filosofía, sujeto y objeto son conceptos artificiales, aunque coyunturalmente indispensables; de allí que, por ejemplo, causa y efecto no deberían reclamar el estatus de categorías concretas, sino - tan sólo - deberían usarse como ficciones convencionales con el propósito de definir, entender y explicar el mundo" (Vásquez Rocca, 2006: 56); esta sería la razón por la cual algunas representaciones son consideradas reales y otras no.

Según Nietzsche, la realidad sería de carácter ficcional, una construcción poética, por tanto, abierta a las posibilidades; la interpretación de la realidad es siempre acorde a los intereses vitales de quien intenta acceder al conocimiento. "El «conocimiento», en todo caso, debe concebirse únicamente como una interpretación, un introducir sentido y no como una explicación vinculada con una perspectiva determinada. El establecimiento de la verdad o de una verdad necesita de la crítica, por lo que su valor debe ser considerado como algo relativo ya que se encuentra determinado por una voluntad de dominio" (Arrocha, 2006: 9). De esta forma y, bajo estos conceptos, se puede articular lo que sería la ficción como conocimiento y el rol que ocupa la estética en la comprensión del mundo. Esto resulta de una relevancia que no se puede desatender, menos en la educación artística, ya que si su objetivo como educación es formar un sujeto integral en cuanto a sus capacidades cognitivas y de relación consigo mismo y con el mundo, se debe tener en cuenta la magnitud de la tarea fuera de los estrechos márgenes que impusieron las Artes Plásticas, las Bellas Artes, o incluso las Artes Visuales.

Si el arte sirve para comprender el mundo, éste es un mundo envuelto en ficciones e integrado. "El hombre es un creador de ficciones, metáforas e interpretaciones, su mundo es siempre un mundo en perspectiva y, por tanto, ficcional. Lo importante es que sea consciente de las metáforas que establece y que no las confunda con la realidad" (Vásquez Rocca, 2006: 57). Lo importante, entonces, para la educación artística debiera ser que los sujetos desarrollen la comprensión y metacomprensión de su "mundo estético" haciendo conciente sus modos de operar en su propia subjetividad.

\section{ARTE PARA CONOCER EL MUNDO: LA CULTURA VISUAL}

Hasta aquí hemos podido ver cómo la forma de conocer y de entender el conocimiento ha ido cambiando y reformulándose, al punto de quedar abierta la posibilidad de una realidad ficcional como objeto de conocimiento, conocimiento ficcional que se organiza respecto a las necesidades y contextos de un sujeto cambiante y en constante movimiento.

Esta conceptualización filosófica y epistemológica sirve de base para contextualizar la problemática educativa de la educación artística en la postmodernidad, haciendo 
frente a estos nuevos desafíos como un cambio en la forma de conocer a través del arte. "Puede ser que el cambio de escenografía no sea simplemente un cambio de decorado entre el primer y segundo acto, sino que en su naturaleza radica la piedra filosofal de la postmodernidad: la fragmentación del yo. El comprender la alteridad, el conocer la existencia de la alternativa, el asumir que la sociedad es, en efecto, una conjugación de individuos y no que la sociedad es una simple extensión del individuo. En otras palabras, que las relaciones epistemológicas en las que se aposentan nuestros distintos tipos de conocimiento, no se dan en un laboratorio sino en un entorno sociocultural integral" (Marin et al., 2003: 432).

En este sentido, cabe destacar la importancia que adjudican los jóvenes al mundo de las imágenes y a la estética en general, en la vida cotidiana y en la incorporación y modelación de sus identidades, muchas veces de forma inconciente y sin orientación. Del mismo modo, "la cultura visual tendría un objeto de estudio caracterizado por los artefactos materiales (edificios, imágenes, - fijas y en movimiento - representaciones en los medios de masas, las performances...) producidos por el trabajo o la acción y la imaginación de los seres humanos con finalidades estéticas, simbólicas, rituales o político-ideológicas, o con finalidades prácticas dirigidas al sentido de la mirada, o un significado expandido" (Hernández, 2000: 140).

De aquí la importancia de la cultura visual como una de las preocupaciones principales de la educación artística, ya que aborda un conocimiento comprensivo del mundo, del mundo personal y colectivo impregnado de imágenes y sobreestetizado al punto de perder los límites de la realidad y la ficción. "El campo del arte en la actualidad, se caracteriza por la disolución de sus límites (tanto en los medios, como en los conceptos), lo que lleva a que las manifestaciones y los objetos artísticos se muestren para ser comprendidos (en su significación), más que para ser vistos (como estímulos visuales)" (Hernández, 2000: 43).

Estas nuevas concepciones de arte ya eran previstas décadas atrás como se señala a continuación:

\footnotetext{
"En un tiempo muy distinto del nuestro, y por hombres cuyo poder de acción sobre las cosas era insignificante comparado con el que nosotros poseemos, fueron instituidas nuestras Bellas Artes y fijados sus tipos y usos. Pero el acrecentamiento sorprendente de nuestros medios, la flexibilidad y la precisión que estos alcanzan, las ideas y costumbres que introducen, nos aseguran respecto de cambios próximos y profundos en la antigua industria de lo Bello. En todas las artes hay una parte física que no puede ser tratada como antaño, que no puede sustraerse a la acometividad del conocimiento y la fuerza modernos. Ni la materia, ni el espacio, ni el tiempo son, desde hace veinte años, lo que han venido siendo desde siempre. Es preciso contar con que novedades tan grandes transformen toda la técnica de las artes y operen, por tanto, sobre la inventiva, llegando quizás hasta a modificar de una manera maravillosa la noción misma del arte" (Valéry, 1928: 3).
}

De esta forma, si antes la estética se encargaba de la obra de arte y el concepto de belleza, hoy se encarga de los conceptos y de sus construcciones y deconstrucciones hechas en la imagen, en el producto artístico, en la visualidad y la ficción como conocimiento; no por nada, los nuevos medios artísticos se trasladan de las galerías a la red en Internet, o a la pura acción, tomando de la cotidianeidad estética sus materiales conceptuales para crear nuevos mundos. 
Esta fuente inagotable de material visual-conceptual que se desprende de la cultura visual, ha sido aprovechada por los artistas actuales para comprender el mundo y el devenir del arte. Por otra parte, en las escuelas, por lo general, se sigue enseñando un Arte de culto, culto a la belleza, a ciertos cánones, a ciertas formas de trabajar y a ciertos materiales que podríamos denominar como tradicionales, mientras la visualidad viva, esa que todos consumen pero no comprenden, genera las realidades cambiantes a las que nos intentamos adaptar. "Muchos autores buscan la manera de paliar las consecuencias de la hiperestetización de una sociedad que se comunica a través de la apariencia y que no profundiza en el contenido de los mensajes visuales y audiovisuales. Algunos ven en la educación artística la solución a la falta de actitud crítica frente al continuo bombardeo de imágenes. Desde la enseñanza del arte se puede preparar a la sociedad para la lectura y el uso del lenguaje visual. Y es que el arte nos puede enseñar a conocer mejor el mundo en el que vivimos" (Megías, 2007: 84). En efecto, si en el arte ya no existen restricciones en cuanto a su medios de producción e interpretación, abarcando un sin fin de posibilidades a través de la cultura visual, la tecnología y los nuevos medios, no debería tampoco existir restricciones a la hora de hablar de Arte en las escuelas; Arte puede ser sinónimo de hacer y estar en el mundo.

Esta postura encierra no sólo un valor como conocimiento estético y artístico entendidos tradicionalmente, sino, además, un valor cognoscitivo, crítico y ético para el desarrollo de un individuo conciente de sí mismo y de los efectos docilizadores y anestesiantes de la industria visual; la aparición del cine y la capacidad de reproducir las creaciones artísticas visuales generaron una masificación repentina de la estetización, en que el espectador quedó sometido al impacto visual sin una capacidad reflexiva; la cultura pop y del espectáculo se confunde con lo artístico, todo junto conforma un mar de significados que sin una recepción crítica y comprensiva genera un estado de alienación en los receptores pasivos. "Resulta patente que esto es la realización acabada del «art pour l'art». La humanidad que antaño, en Homero, era un objeto de espectáculo para los dioses olímpicos, se ha convertido ahora en espectáculo de sí misma. Su autoalienación ha alcanzado un grado que le permite vivir su propia destrucción como un goce estético de primer orden" (Benjamin, 1989: 20).

No solamente el cine y la fotografía han cambiado la forma de acercarse al conocimiento y de construir nuestra imagen de mundo; también los nuevos medios de comunicación e información han configurado una nueva sociedad, multicultural, mestiza, que termina en una sociedad sin ideologías y con la necesidad de construir un mundo sin esos andamiajes. De la misma forma, los sujetos intentan construir una identidad estética basada en el consumo. A partir de este fenómeno, el arte ha puesto sus esfuerzos en colgarse de las nuevas redes y medios de comunicación e información; colgarse digo, porque lo que ha hecho es infiltrarse como parásitos en los nuevos medios para reconstruirlos, y con ello, transformar la realidad, crear nuevas realidades o posibles realidades. Esto constituye una forma de conocer la realidad, ya que logra develar lo que está bajo la estructura superficial de los medios y mostrar el nuevo paradigma postmoderno, la capacidad que tiene la realidad, y por tanto el sujeto, de cambiar, es decir, de mutar y crear una realidad "a la medida".

El problema aquí es cómo se forma la identidad de un sujeto con tales libertades, o más bien posibilidades, y cómo se constituyen los valores tomando esto en cuenta. Lo que parece responder a estas preguntas es la nueva moralidad que dice que cualquiera 
puede ser lo que quiera; se puede cambiar de sexo, tener un duplicado virtual en Internet, cambiar la vestimenta, rehacer el mundo estéticamente. Además, "Somos capaces de justificar las guerras y los crímenes más deleznables simplemente porque son promovidos por nuestros propios intereses, y no utilizamos sólo los medios de comunicación para justificarlos sino para moralizarlos, y hasta para terminar acomodando a los tibios y disconformes o para anatematizarlos en caso de inadaptación. Y los retransmitimos mientras nos alimentamos, para que nuestros hijos lo contemplen y participen de ello, porque este tipo de programas son «para todos los públicos». Los medios y las nuevas tecnologías se erigen en las iglesias de la nueva religión, catedrales virtuales de una moralidad social emergente" (Arañó, 2002: 191). Éste es un problema que viene a revitalizar la importancia de la formación estética y del arte, ya que sin ella, los jóvenes están a merced del flujo de información y consumo estético (incluido el arte) sin una reflexión propia, sin un autoconcepto propio; quedan a la deriva, expuestos a los intereses promovidos por los medios masivos de comunicación e información.

Al hablar de formación estética debemos referirnos primero al recorrido de este concepto especialmente desde Kant a Hegel. Para el primero, la estética tenía como objetivo el juicio del gusto, es decir, que la actividad artística que es originaria del espíritu no podía conceptualizarse; en cambio para Hegel, los aspectos cognitivos resultan inseparables de dicha actividad, por lo tanto, serían materia de estudio de la filosofía de la ciencia en tanto se centra en el conocimiento artístico. "El papel predominante que la filosofía de Hegel ha tenido en la configuración cultural de nuestra época, lleva consigo el que, aunque teóricamente se continúe hablando del objeto de la estética en términos de juicio de gusto, en la práctica, la discusión estética actual esté centrada en los aspectos cognoscitivos de la experiencia estética, así como en la relación existente entre arte, conocimiento y verdad" (Labrada, 2007: 80).

Para Hegel debe existir una ciencia del arte, pues en él se encierran conocimientos que es preciso revelar; ya que se razona el goce y las impresiones, todo en la obra es materia de crítica y de observaciones. "La ciencia del arte, en semejante época, es una necesidad mayor que en aquellos tiempos en los cuales tenía el privilegio de satisfacer plenamente y, por sí misma, la inteligencia. Hoy parece invitar a la filosofía a que se ocupe de él; no para que ésta lo conduzca a su fin, sino para que estudie sus leyes y profundice en su naturaleza" (Hegel, 2006: 18); en este sentido esta profundización en la naturaleza del arte es una profundización en la naturaleza del ser humano y su realidad. "Pensar el arte es, ahora, pensar lo posible para el arte y, también, que todo es posible en el arte (aún cuando no todo fuera deseable). Si el espectro de lo posible se ha desplegado, el pensamiento creador se enfrenta para su consideración a su dilema más difícil: elegir. En esta tarea el papel de la educación artística y de la creación es fundamental para enfrentarse al desprecio y al falso aprecio artístico" (Diez, 2001: 144). Esta evolución en la delimitación del concepto de estética y filosofía del arte, es la que conducirá a entender la estética como una forma de comprender el mundo y el arte como conocimiento, más aún hoy, en que éste se desborda en una cultura sobreestetizada.

A raíz de las nuevas formas de Arte sumadas a la nueva orientación epistemológica y perdido el sentido racional y metafísico de la Verdad, los parámetros para una formación estética se abren a las posibilidades de lo indeterminado. Todo puede ser arte y cualquiera puede ser un artista; es lo que comienza a mostrarse en el arte del último siglo; es lo que nos revela Duchamp con su urinario en una galería, y es lo que los nuevos medios 
reclaman. El arte se desbordó en una complejidad que debe ser abordada con una nueva formación estética. "En la expansión del propósito de obrar con conocimiento, la creatividad jugará un papel fundamental en la presencia artística y en la necesaria realidad de su mediación. Se trata de la creatividad que implica el desarrollo integral de la libertad de la persona y la cognición individual que supone la aprehensión de la realidad y el mecanismo de la obra de arte" (Diez, 2001: 150). Esto último supone una formación estética centrada en una cultura visual contextual, propia del sujeto, de su entorno y de sus procesos creativos. La reflexión estética se moverá en función de las necesidades creativas del sujeto que aprende a través del arte y formando una identidad en conexión con la cultura visual, asumiendo una postura crítica y reflexiva en torno a sus propias representaciones del mundo y de sí mismo.

\section{EDUCACIÓN EN ARTES VISUALES, CULTURA VISUAL Y CONSTRUCCIÓN DE LA SUBJETIVIDAD JUVENIL}

Al hablar de construcción de la subjetividad o identidad, se asume que no existe una igualdad o una acción de homogeneización, en una sociedad como la chilena donde conviven formas de vida posmodernas con algunas preindustriales, en regiones compartidas por diferentes etnias y formaciones culturales, realidades urbanas y rurales que llevan a claras diferencias sobre la percepción de la vida, incluso diferentes percepciones sobre los tramos de edad que constituyen la juventud; se vuelve necesario aproximarse al tema en base al respeto a la diferencia como la piedra angular de la construcción de una identidad común. Según Cajías (1995) la identidad se construye sobre, al menos, cuatro pilares: la creatividad, la recuperación de la memoria colectiva, la organización y la formación. Por ello, indicadores como el desarrollo de las expresiones artísticas propias del trabajo colectivo y voluntario, de la autoestima, de la autodeterminación, del ejercicio real de la democracia y del pensamiento crítico, son fundamentales para entender su proceso de constitución.

Para situar lo dicho en el contexto latinoamericano y chileno, específicamente, es relevante mencionar lo que podría denominarse como la muerte de las utopías. Esto, en relación a los cambios producidos en las últimas décadas del siglo XX con la irrupción de los regímenes autoritarios y los cambios de conducción por los intereses económicos, y luego un retorno a la democracia de la mano de la avanzada globalización con todas las implicancias a nivel cultural y económico que ello significa. Es especialmente a raíz de estos cambios donde los jóvenes comienzan a demostrar el estancamiento y la falta de participación que muchas veces les impide formar una identidad cohesionada con el entorno social. "En el marco de un discurso global de fin de las ideologías y del pragmatismo político, la oferta de participación democrática aparece pobre y formal, pues va acompañada del "reajuste" de la economía donde al joven (principalmente de los sectores populares) le resulta cada vez más difícil insertarse y cuya seguridad educativa y de salud se ve sustantivamente reducida" (Cajías, 1995: 3).

Así surge una nueva cultura juvenil a partir de los años sesenta, que se caracteriza por desvincularse de la participación ciudadana y de las tradiciones locales para reemplazar los modelos convencionales (padres, instituciones, religiones) por los pares; esto, enmarcado en el contexto de una globalización en expansión, la aparición de una "comunidad 
mundial" donde se yuxtaponen culturas en tiempos distintos y en situaciones de desarrolo diversas, con creencias completamente distintas, origina una suerte de relativización y deconstrucción del modelo de futuro. "Un futuro que sólo balbucean los relatos de ciencia-ficción en los que los jóvenes encuentran narrada su experiencia de habitantes de un mundo cuya compleja heterogeneidad no se deja decir en las secuencias lineales que dictaba la palabra impresa, y que remite entonces a un aprendizaje fundado menos en la dependencia de los adultos que en la propia exploración, que los habitantes del nuevo mundo tecno-cultural hacen de la imagen y la sonoridad, del tacto y la velocidad" (Barbero, 2002: 2).

Probablemente, los fracasos o dificultades de la formación valórica y de la orientación educacional para la formación de la identidad de los jóvenes, es consecuencia de la imposición de un "Modelo" que no responde a los requerimientos y experiencias de los jóvenes actuales; si antes los jóvenes conservaban esa empatía con sus "modelos", fueran estos los padres, profesores o personas con autoridad y experiencia, hoy la empatía se vuelca hacia la cultura tecnológica y visual, que va de la información absorbida por el adolescente en relación con la cultura visual predominante, la televisión, hasta la facilidad casi natural con que se manejan en la compleja red informática. Estaríamos ante una nueva sensibilidad compuesta por aspectos cognitivos y expresivos, ya que es en los conceptos de fragmentación, navegación, relato, velocidad, sonido e imagen entre otros, en los cuales los adolescentes encuentran sus referentes para construir su identidad. "Estamos ante la formación de comunidades hermenéuticas que responden a nuevos modos de percibir y narrar la identidad, y de la conformación de identidades con temporalidades menos largas, más precarias pero también más flexibles, capaces de amalgamar, de hacer convivir en el mismo sujeto, ingredientes de universos culturales muy diversos" (Barbero 2002:4).

El problema no es sólo que los alumnos y alumnas aprendan los conocimientos impuestos para la inserción en sociedad como el que alumnos y alumnas cada vez más enfrenten la responsabilidad de construir sus identidades y sus nociones de realidad, y mientras la escuela sigue consumiendo cantidades de recursos en trasmitir conocimientos "académicos" pretendidamente científicos y dotados de una supuesta superioridad frente a otros saberes, parece no dar importancia a la complejidad que se desarrolla a su alrededor, en la que se manejan cantidades de información y taxonomías mucho más abiertas que las de la escuela, para construir una sociedad concreta. Es en esta complejidad social, simbólica y estética donde los jóvenes necesitan las herramientas que les permitan tener un juicio formado, poder procesar, reconstruir y operar desde un posicionamiento responsable y ético.

A modo de conclusión, cabe destacar que el dinamismo expuesto en estos antecedentes sugiere la necesidad de comprender la enseñanza de las artes bajo un paradigma que logre dar cuenta de la complejidad y profundidad de sus fenómenos. Se requiere un mayor énfasis en la investigación educativa en el área artística, ya que si bien, existen actualizaciones curriculares pertinentes a estos tiempos, es necesario comprender los procesos en que las teorías se "traducen" en las prácticas docentes. Cómo circulan los saberes en torno a la llamada Cultura Visual entre los profesores de Enseñanza Media, qué conexiones establecen, cómo dialogan con estos conceptos, cómo traducen, se apropian, reinventan, descartan ciertas nociones, qué significa la enseñanza del Arte basada en la Cultura Visual para estos profesores. Así, a partir de este proceso de investigación 
reflexivo y de re-construcción de sus prácticas, el docente podría contribuir en su propio proceso de formación, bajo una postura dialéctica en que él es involucrado en un proceso de aprendizaje colaborativo, para transformar la práctica educativa.

\section{REFERENCIAS BIBLIOGRÁFICAS}

Arañó, J. (2002). Cibermodernidad o La Educación Artística de Pokemon. Arte, individuo y sociedad. Consultado en julio 152009 en: http://revistas.ucm.es/bba/11315598/articulos/ ARIS0202110187A.PDF

Arrocha, R. (2006). Federico Nietzsche: la sabiduría de la ilusión como inversión del platonismo. Extramuros. Consultado en 28 Julio 2009 en: http://www2.scielo.org.ve/scielo.php?script=sci_ar ttext\&pid=S131674802006000100014\&lng=es\&nrm=iso $>$.ISSN 1316-7480

Ávila, F. (2002). Filosofía, Epistemología y Hermenéutica en el Pensamiento de Richard Rorty. A Part Rei Revista de Filosofía. Consultado en julio 24, 2009 en http://serbal.piteresidete es/ cmunoz11/inveslibre.pdf

Barrera, C. (1995). Ideas sobre el arte y el juego en la filosofía de Federico Nietzsche de Los Andes. Consultado en julio 27, 2009 en: http://www.scientificcommons.org/17623507

Baudrillard, J. (1978). Cultura y Simulacro. Kairós. Barcelona.

Benjamín, W. (1989). La obra de arte en la época de su reproductibilidad técnica. Publicado en Benjamín, Walter Discursos Interrumpidos I. Buenos Aires: Taurus.

Bentolila, H. (2006). El giro comprensivista de la ciencia y la desfundamentación lingüística de la experiencia. Universidad Nacional Del Nordeste. Chaco, Argentina. Consultado en julio 25 2009 en http://www.unne.edu.ar/Web/cyt/cyt2006/02-Humanidades/2006-H-028.pdf

Bolívar, A. (2004). El conocimiento en la Enseñanza, explicar, comprender, transformar. Salusvita, (Bauru, 5:17-42.

dajías, H. (1999). Estigma e identidad. Una aproximación a la cuestión juvenil.

Consultado el 5 de septiembre de 2009. Disponible en: http://redalyc.uaemex.mx/redalyc/ pdf/195/19501008.pdf Última Década,

Eebrián A. (1999). Algunas Dimensiones Negativas De La Globalización En Ibero América. El Ejemplo De Guatemala. Scripta Nova, n.45 Consultado en Septiembre de 2009 en http://www. ub.es/geocrit/sn-45-10.htm

Gooper D. (2007). Ideología y Tribus Urbanas. Santiago: LOM.

Derrida J. (1968). La Diferencia. Edición electrónica de www.philosophia.cl. Escuela de Filosofía Universidad ARCIS. Consultado en julio 23, 2009 en: http://www.ddooss.org/articulos/textos/ Derrida_diferencia.pdf

Diez, J. (2001). Cognición contextual en la creatividad y en el aprendizaje de la creación artística. Arte, Individuo y Sociedad. Consultado en julio 12, 2009 en: http://revistas.ucm.es/bba/11315598/ articulos/ARIS0101110143A.PDF.

Hegel, F. (2006). Estética, Sistema de las Artes. Libertador : Buenos Aires

Hernández, F. (2000). Educación y Cultura visual. Octaedro: Barcelona

Gabrada, M. A. (2007). Estética y Filosofía Del Arte: Hacia Una Delimitación Conceptual Servicio de publicaciones de la Universidad de Navarra. Consultado en julio 122009 enhttp:// dspace.unav.es/dspace/bitstream/10171/2173/1/04.\%20MAR\%C3\%8DA\%20ANTONIA\%20 LABRADA, \%20Est\%C3\%A9tica\%20y\%20Filosof\%C3\%ADa\%20del\%20Arte\%20hacia\%20 una\%20delimitaci\%C3\%B3n\%20conceptual.pdf. 
Magendzo A, Donoso P. y Rodas M. (1998). Los objetivos transversales de la educación. Santiago: Editorial Universitaria.

Marin, R. (2003). Didáctica de la educación artística para primaria. Pearson: Madrid.

. BSÎO\#\#BSCFP

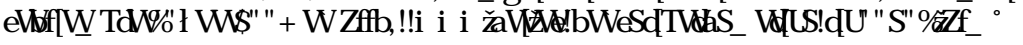

Megías, C. (2007). Arte para conocer y cambiar el mundo. Propuesta educativa desde una perspec$\square$ tiva sociológica. Arte, Individuo y Sociedad. Consultado en julio 23, 2009 en http://revistas. ucm.es/bba/11315598/articulos/ARIS0707110081A.PDF

Molina, G. (2004) La Soberana Indeferencia: sobre el carácter reflexivo de la subjetividad moderna.

Mombrada, 1, 185-207.

Aoreno P. (2001). Escenarios Para La Educación En El Contexto De La Globalización y La Postmodernidad. Aportes, V.6, 16.

Muñoz, J. J. (1998). De la crítica estructuralista a la disolución de la estética, el lenguaje y la

realidad. Especulo. Revista de estudios literarios. Consultado en julio 24, 2009 en http://www.

ucm.es/info/especulo/numero10/estruct1.html

Muñoz, B. (1993). Sociología de la cultura de masas. Madrid: Universidad Carlos I. Consultado 0 en marzo de 2008 desde http://inicia.es/de/cgarciam/Munoz.html

Ortega y Gasset, J. (1962). La Deshumanización del Arte. El Objeto Estético. Revista de Occidente. Rorty, R. (1996). Consecuencias del pragmatismo. Tecnos: Madrid.

Saenz, J. (2003). Pedagogía y Epistemología; Hacia una pedagogía de la subjetivación. Bogotá: Magisterio.

Urreiztieta, M. (2004). La Sociología Interpretativa: Globalización y Vida Cotidiana. Caracas: Universidad Simón Bolívar.

\aléry, P. (1928). La Conquête de L'ubiquitê. Consultado en julio 22, 2009 en: http://classiques.

uquac.ca/classiques/Valery_paul/conquete_ubiguite/valery_conquete_ubiquite.pdf

ఫásquez Rocca, A. (2006). El giro estético de la epistemología. La ficción como conocimiento,

subjetividad y texto. Aisthesis. Consultado en julio 24, 2009 en: http://www.puc.cl/estetica/

html/revista/pdf/Adolfo_Vssquez.pdf

\attimo, G. (1992). El pensamiento débil. Madrid: Cátedra.

Wellmer, A. (1993). Sobre la Dialéctica de la Modernidad y la Postmodernidad. La crítica de la razón después de Adorno. Madrid: Visor. 